\title{
Variations and risk of extreme precipitation events with sub-daily data: a case study in the Gangjing river basin
}

\author{
Guangxu Liu ${ }^{1 *}$, Aicun Xiang ${ }^{1}$, Zhiwei Wan ${ }^{1}$, Yang Zhou ${ }^{2}$, Jie Wu ${ }^{1}$, Yuandong Wang ${ }^{1}$, Sichen Lin ${ }^{1}$ \\ ${ }^{1}$ School of Geography and Environmental Engineering, Gannan Normal University, Ganzhou 341000, China \\ $5{ }^{2}$ Department of Agricultural Economics and Rural Development, Renmin University of China, Beijing 100872, China
}

Correspondence to:Guangxu Liu (lg760411@126.com)

\begin{abstract}
Climate warming increases flooding risk and the intensity of extreme precipitation. Studying changes and trends of extreme precipitation events is key in term of reducing flood risk and disaster loss. This paper investigates the thresholds, changes and time scales of extreme precipitation using sub-daily records in meteorological stations in the Ganjiang river

10 basin. We use Gamma distribution and choose L-moment method to estimate parameters. Results show that (1) precipitation events with very long duration occur rarely and have minimal contribution to the total precipitation; (2) Extreme precipitations have the characteristics of occasional but sudden occurrence in summer and spring and the intensity and occasional probability will increase in spring in the future in Yifeng, Zhangshu and Ningdu; (3) Risks were positively correlated with elevation in the northern plain and Jitai Basin in the midstream area while risks in the southern hilly area

15 were negatively correlated with elevation. These findings should be helpful in adjusting regional land use planning and for emergency preparedness including risk management and relief operations in high-risk areas in the future.
\end{abstract}

\section{Introduction}

The hydrological cycle is expected to intensify with global warming, which likely increases the intensity of extreme precipitation events and the risk of flooding(Tabari, 2020). Extreme weather events such as storms have occurred frequently around the world in recent years, which often cause disastrous floods and landslides, resulting in great casualties and economic losses. Zhengzhou city in China experienced a rare and continuous heavy precipitation process from July 18th to July 21st in 2021. Extreme precipitation intensity reached $201.9 \mathrm{~mm}$ in an hour and cumulative precipitation reached 449 mm, which caused 292 deaths and 47 missing, 65.5 billion yuan lost and 44,209.73 hectares crops affected (Encyclopedia, 2021). Eight days before Zhengzhou storm, parts of Rhineland-Palatinate and North Rhine-Westphalia in Germany were also encountered heavy precipitation of 148 litres of rain per square meter within 48 hours, causing severe flash flooding. As of July 23, 2021, the death toll from the flood in western Germany reached 180 People and about 150 people are missing. The reconstruction funds reach billions of euros. Changes in extreme precipitation are among the most impact-relevant consequences of climate warming (Pfahl et al., 2017). IPCC reported that the globally averaged combined land and ocean surface temperature had showed a warming trend of $0.85^{\circ} \mathrm{C}\left[0.65^{\circ} \mathrm{C}\right.$ to $\left.1.06^{\circ} \mathrm{C}\right]$ over the period 1880 to 2012 and continued 
30 emission of greenhouse gases will cause further warming in the future(Pachauri et al., 2014). The continuous warming breaks the original energy balance of the climate system, causing abnormalities in the atmospheric circulation and water circulation system, which in turn causes an increase in extreme precipitation events and discharges. Theoretical models predict that extreme precipitation intensity could exponentially increase with warming at a rate determined by the ClausiusClapeyron (C-C) relationship (Trenberth, 1999; Trenberth et al., 2003). An increase in the frequency of extreme

35 precipitation events has increased at high and mid-latitudes of the land as a likely consequence of the climate warming (Rodrigo 2010). A rate of $6 \%$ to $10 \%$ increases per degree of warming has been observed in annual maximum daily precipitation over land (Asadieh \& Krakauer, 2015; Westra et al., 2013). Climate models project shows that extreme precipitation will continue to increase in the 21 st century at approximately the same rate because of continued warming (Fischer et al., 2013; O’Gorman \& Schneider, 2009; Pendergrass \& Hartmann, 2014; Sillmann et al., 2013). The future trend of extreme precipitation in China is consistent with that of the world. Xiao et al. find that analysis from gauge records for 1971-2013 from 721 weather stations showed maximum hourly summer rainfall intensity has increased by about $11.2 \%$ on average in China which will exacerbate the risks of flash floods in rapidly urbanizing areas (Xiao et al., 2016). Cao and Lu find that the biggest increase of summer precipitation in China from 1961 to 2010 were found in the middle and lower reaches of the Yangtze River (Zeng and $\mathrm{Lu}, 2015$ ), which was caused mainly by the positive contribution of extreme

45 precipitation (Shi et al., 2014). Gao and Xie analysed the response of extreme precipitation to warming in winter in China and found that extreme precipitation would increase by $22.6 \%$ for every $1{ }^{\circ} \mathrm{C}$ increase in winter temperature. This increase is significantly higher than the global average, indicating that extreme precipitation is more sensitive to warming in winter in China (Gao and Xie, 2014). Wu et al. (2014) analysed the changes of extreme climate events under the background of future warming and pointed out that compared with 1986-2005, the total annual precipitation (PROPTOT), the five-day maximum

50 precipitation (Rx5day), heavy precipitation (R95p) would increase in China (Wu et al., 2015). CMIP5 climate model also shows a trend of increasing extreme precipitation events in the future in various regions of China (Zhao et al., 2019). These studies show the importance of studying extreme precipitation changes and trends under climate warming.

An extreme precipitation event can be defined in many ways. Pendergrass thinks that extreme events can be considered if more precipitation falls than those are often appreciated(Pendergrass, 2018). Expert Team on Climate Change Detection

55 Monitoring Indices (ETCCDMI) established several indicators such as CWD10, CWD20, R1 day (annual), R10 mm and R20 mm in undertaking regional analyses for understanding climate extremes and trends(Easterling et al., 2003). Soro et al. grouped the extreme events into two broad categories. One is the yearly extreme events based on heavy daily rainfall. The other is an event-driven extremes characterized by severe flood (Soro et al., 2016). A common definition of extreme precipitation is defined by an event passes a threshold of exceedance or a certain threshold. There are different criteria to 60 define the this threshold, including a fixed absolute value (Brunetti, Maugeri et al. 2004; López-Moreno and Beniston 2009), standard deviation based on statistics and percentile-based threshold (Fernández-Montes, Seubert et al. 2014; Merino, Fernández-Vaquero et al. 2016). Practically, percentile-based threshold such as 95th or 99th percentile of the cumulative 
frequency distribution of daily precipitation with only wet days (or wet hours) is widely used in many researches(Marelle, Myhre et al. 2018; Merino, Fernández-González et al. 2018; Pendergrass 2018; Myhre, Alterskjær et al. 2019). Pendergrass points out that how we defined extreme precipitation affects the conclusions we draw. The reason why researchers focus on extreme precipitation is because extreme precipitation is one of the most frequent weather resulting in floods and landslides which are hazards responsible for damage to buildings and infrastructures, serious social disruption, and loss of human life worldwide each year(Soro et al., 2016). The choice of extreme definition depends on the intended use in term of reducing flood risk and disaster loss.

70 In specific research, researchers used either precipitation observations or simulated data from climate models to study the temporal and spatial variation of the scale and frequency of extreme precipitation. For example, Gao et al. examined the space-time variations of extreme precipitation over monsoon regions in China and assessed the time-varying influences of the climate drivers using Bayesian dynamic linear regression. Results suggest that the central-east and south China is dominated by less frequent but more intense precipitation (Gao et al., 2017). Ren et al. used the $0.5^{\circ} \times 0.5^{\circ}$ daily precipitation data from 1961 to 2011 in the National Meteorological Information Centre and the daily precipitation observations from the meteorological stations in China to investigate changes of extreme precipitation events in South China. The selected index includes the maximum five-day precipitation (RX5day), extreme precipitation (R95), days with precipitation $\geq 20 \mathrm{~mm}$ $(\mathrm{R} 20 \mathrm{~mm})$, continuous precipitation days (CWD) and intensity of daily precipitation (SDII), which are all recommended by the World Meteorological Organization. They find that RX5day, R95, R20mm and SDII have an inter-annual tendency rate

80 of $0.17 \mathrm{~mm} \mathrm{a}^{-1}, 1.14 \mathrm{~mm} \cdot \mathrm{a}^{-1}, 0.02 \mathrm{~d} \cdot \mathrm{a}^{-1}$ and $0.01 \mathrm{~mm} \cdot \mathrm{d}^{-1} \cdot \mathrm{a}^{-1}$, respectively. The proportions of grid points with an increasing trend of RX5day, SDII, and R95 reach 60.85\%, 75.32\%, and 75.74\% respectively (Ren, Zhang et al. 2014).. Pfahl et al. decompose the forced response of daily regional scale extreme precipitation in climate-model simulations into thermodynamic and dynamic contributions using a robust physical diagnostic to study the regional pattern of projected changes in extreme precipitation. Pfahl et al. find that thermodynamics alone would lead to a spatially homogeneous

85 fractional increase in most regions throughout the globe. The dynamic contribution amplifies increases in the Asian monsoon region but weakens them across the Mediterranean, South Africa and Australia. They think that the dynamic contribution is a key to reducing uncertainties in future projections of regional extreme precipitation(Pfahl et al., 2017). Mukherjee et al. studied the gridded observations and simulations from the Coupled model inter-comparison project 5 (CMIP5) and Climate of 20th century plus $(\mathrm{C} 20 \mathrm{C}+)$ detection and attribution $(\mathrm{D} \& A)$ project and find that the frequency and intensity of extreme precipitation events have increased in India during the last few decades and anthropogenic warming has a significant contribution to the rise of the frequency of extreme precipitation(Mukherjee et al., 2018). Talchabhadel et al. analysed the spatial distribution of monthly and annual precipitation and 1-day extreme precipitation and their trends with the records from 291 stations across Nepal for the period of 1966-2015. The result shows that extreme precipitation events increase in western mountainous regions in the recent decades (Talchabhadel et al., 2018). Bao et al. analysed daily extreme precipitation events in several Australian cities and found future daily extremes increasing at rates faster than those inferred 
from observed scaling (Bao et al., 2017).

These researches use daily precipitation to analyse extreme events. However, event with scales shorter or longer than one day also pose flood risk. Merino et al. explain that daily databases would bring uncertainty in analysing flood risk with two examples (Merino et al., 2018). One is that two extreme precipitation events with the same precipitation amount but the occurred over 12 consecutive hours. Another example is that a precipitation event below the extreme precipitation threshold posed flood risk because it began on one day and ended the next and total amount was high but not recorded. It is key to analyse precipitation event periods, that is, the time scales of precipitation. Besides extreme precipitations pose a threat to human society because they may cause floods leading to loss of life and property(Tabari and Willems, 2018). Whether extreme precipitation can cause floods is regional differences. For example $50 \mathrm{~mm}$ daily precipitation may have a weak impact on human society in plain areas or humid areas, but It may cause flash flood and even landslides and debris flows in mountain areas or arid areas(Tabari and Willems, 2018). Time distribution patterns and return levels of extreme precipitation should be analysed in flood risk research locally ( $\mathrm{Wu}$ et al., 2018). Furthermore, engineering constructions in disaster mitigation and prevention usually follows a standard design flood of a certain return period. With climate warming the intensity of extreme precipitation has increased significantly. Projects constructed in accordance with the past flood control standards have the risk of increased losses. According to the annual report of road flooding statistics, the annual direct economic loss of road infrastructure caused by flood damage has reached 10 to 30 billion yuan in China in the past 10 years (Li, Zhang et al. 2014). Analysing the changing trend of extreme precipitation and proposing a design standard for future flooding preparedness is of great significance to improving the disaster prevention and mitigation system (Xu, Ma et al. 2014;

115 Chen 2015).

Collectively, this analysis focusses the objectives as below: to investigate the thresholds of extreme precipitation using subdaily records in meteorological stations in the Ganjiang river basin; (2) to identify the changes and time scales of extreme precipitation using probability distribution and M-K test; (3) to explore the flood risk caused by extreme precipitation with different time scales and return period in a case study.

\section{Study area}

The study area comprises the Ganjiang basin which is located with longitude spanning from 113.74-116.63E and latitude spanning from $24.57-29.07 \mathrm{~N}$ in the southeast of China (Figure 1). The drainage area is about $81,244 \mathrm{~km}^{2}$. The Ganjiang River is the major inflows which is originate from the south and flows into the Poyang Lake in the north. The extreme precipitation events in this watershed depend heavily on the wind-facing mountains, precipitation amount and precipitation timing. The topography is characterized with mountains mainly distributed in the south and alluvial plains in the north. The Jiulian mountain is the southwestern boundary. The Wuyi Mountain forms the east border. The elevation is uplifting gradually from the north to the southeastern end, which result in a higher precipitation in the mountainous northwestern area 
and a lower rainfall zone in the central basin and the lower reach in the north (Hu et al., 2013). Apart from the moderating effects due to changes in topography, quasi-stationary front, monsoon and typhoons systems also control precipitation patterns. The average annual precipitation ranges between 1400 and $1600 \mathrm{~mm}$ (Li et al., 2017). Due to the long existence of quasi-stationary front over the basin, over $70 \%$ of the annual precipitation occurs during the period from April to June. Monsoon and typhoon rainstorms frequently occur between July and September. This area is characterized by a highly variable hydro-climate and flood-prone area in China. Fluvial floodplain deposition investigations indicates that the Ganjiang basin have experienced 18 big floods during the past 130 years (Liu et al., 2018).

\section{Data and methods}

\subsection{Precipitation Data}

The precipitation data are collected from 12 national basic meteorological observation stations in Figure 1 supplied by the National Meteorological information Centre in China. These stations scatter from latitude $24.87 \mathrm{~N}$ to 28 . $60 \mathrm{~N}$ and longitude 113.95E to $116.02 \mathrm{E}$ (Table 1). The highest station is Jinggangshan (Jgs) with an elevation of 843 meters above the sea level

140 ( $\mathrm{m}$ a.s.l) and the lowest one is Zhangshu (Zs) with an elevation of $30 \mathrm{~m}$ a.s.l. Four stations Yifeng (Yf), Zs, Lianhua (Lh) and Longnan (Ln) began observing in 1951. Ningdu (Nd)) and the others all began in the end of 1950s. All these stations have been well maintained and managed since 1950s. Twelve hourly (12-H) precipitations between 1959-1-1 and 2016-12-31 were sliced with the purpose to keep the data consistency. The 12-H intervals were composed of the periods from 8:00 to 20:00 and 20:00 to 8:00 the next day. The data precision is $0.1 \mathrm{~mm}$. The suppliers assessed the data quality with several

145 assay controls and detection limits. The erroneous or likely-erroneous data were all manually verified and corrected. Particular attention has been paid to the problems arising from inhomogeneities of data series, which were validated and corrected according the methods supposed by Wang in 2008 (Wang, 2008). The change points were detected by integrating a Box-Cox power transformation procedure into a common trend two-phase regression model based test (the transPMFred algorithm). The detected change points were adjusted with a quantile matching (QM) algorithm (Wang et al., 2010).

150 Then a precipitation event is determined by rainfall above the threshold of $0.1 \mathrm{~mm}$ in 12 hours (12-H) from 8:00 to 20:00 in the day or 20:00 to 8:00 in the night in this paper. Considering the high seasonal variations of precipitations in the study area, the investigation was performed season by season. Therefore, the data was divided into four seasons, where winter data refers to the records in December, January, and February; spring, March, April, and May; summer, June, July, and August; and autumn, September, October, and November. 


\section{$155 \quad 3.2$ Definition of extreme precipitation}

The definition of extreme precipitation should be chosen with care and articulate it clearly (Pendergrass, 2018). Many researches have discussed the definition of what constitutes an extreme event (Saidi et al., 2015). These definitions are grouped into two categories (Easterling et al., 2000).

(1) extreme events based on intensity such as yearly or seasonal maxima, CWD10, CWD20, R1 day (annual), R10 mm and

160 R20 mm indices from the Expert Team on Climate Change Detection Monitoring Indices (ETCCDMI) (Soro et al., 2016). Yearly or seasonal maxima are one of the commonly used extreme value sampling. It generates annual maximum series whose sample size is identical with the number of years. Yet this definition does not include all extreme values because any second highest would be dropped out (Saidi et al., 2015).

(2) Events over a threshold (EOT), referred to as the extreme frequency (Haylock and Nicholls, 2000), is the other definition.

165 EOT is characterized by physical expected impacts, such as floods or hurricanes. Pendergrass investigated thresholds such as the 99th percentile of the cumulative frequency distribution, the 95th percentile the and the 90th percentile and found that the way to define extreme precipitation would affect the conclusions (Pendergrass, 2018).

The main impact of extreme precipitation on humans is to cause flood disasters while flood disasters often occur several times in some years and are missing in other years. Therefore, a threshold of 99th percentile is selected to define extreme precipitation in this paper, which is calculated based on all rainy events from 1959 to 2016. According to this threshold, extreme precipitation can occur up to four times a year, which is consistent with the flood observation records.

\subsection{Method to analyse extreme precipitation events}

The goal of the return period analysis is to estimate the value of the event magnitude corresponding to a given probability. To have a true return period of extreme precipitation is an information problem (El Adlouni and Ouarda, 2010). It could be

175 precisely determined by a frequency distribution if there were sufficiently long record of precipitation. In this study, there are only 59 years of rainfall records, which forces us to use a limited amount of observations to estimate events with a chance of 1 in 100 years or even more, i.e., exceedance probabilities of one percent or more. The addressed problem is solved in practice by estimating probability distributions. Such distributions involving precipitation research mainly includes: Gamma, Generalized Extreme Value and Pearson type 3 distributions. Gamma distribution is one of the most popular models for

180 describing precipitation (Papalexiou et al., 2013), which could provide the best fit for rainfall distribution (Şen and Eljadid, 1999).

Gamma distribution belongs to the exponential family (Papalexiou et al., 2013). It is used to fit positive data and is a good representation of rainfall distribution. Assuming that the precipitation in a certain period is $\mathrm{x}$, the probability density function that satisfies the Gamma distribution is 
$185 G(x)=\frac{1}{\beta^{\alpha} \Gamma(\alpha)} x^{\alpha-1} e^{-x / \beta}$

Where $\alpha$ is the shape parameter, $\beta$ is the scale parameter, and $\mathrm{x}$ is the precipitation records. $(\alpha, \beta)>0$ when $x>0$ and $(x ; \alpha, \beta)$ $=0$ when $x \leq 0 . \Gamma(\alpha)$ is the Gamma function, and its probability function is:

$$
\Gamma(\alpha)=\int_{0}^{\infty} y^{\alpha-1} e^{-y} d y
$$

The L-moment method (LM), along with the moment and maximum likelihood methods, was often applied to samples taken from simulated gamma distribution (Kliche et al., 2008). LM are linear combinations of order statistics (L-statistics) analogous to conventional moments and can be used to summarize the shape of a probability distribution (Hosking, 1990). LM of a probability distribution of random variable $\mathrm{X}$ are defined in terms of a linear combination of probability weighted moments (PWM) by Hosking (Hosking, 1990). LM have many advantages: they are less sensitive to outliers in the data, approximate their asymptotic normal distribution more closely, are nearly unbiased for all combinations of sample sizes and populations, and can characterize wider range of probability distributions than conventional moments. As literature (Vivekanandan, 2015), LM are used to sample the precipitation for determining parameters $\alpha$ and $\beta$ in this paper. The sample L-moments can be computed as the population L-moments of the sampleAssume that the variable $X$ follows a certain distribution function and $n$ is sample values of the observed variable $x$. The $n$-values are sorted in ascending order and $X_{j: n}$ is used to represent the $j$-th value, i.e. $X_{1: n} \leq \ldots \leq X_{j: n} \leq \ldots \leq X_{n: n}$. The sample L-moments of the first 2 orders in a finite sample of $n$ observations are calculated as follows (Wang, 1996):

$l_{1}=b_{0}$

$l_{2}=2 b_{1}-b_{0}$

$b_{0}=n^{-1} \sum_{j=1}^{n} x_{j: n}$

$b_{1}=n^{-1} \sum_{j=2}^{n} \frac{j-1}{n-1} x_{j: n}$

The L-mean, L-variation of the sample series are defined as follows:

$l_{1}=b_{0}$

$t_{2}=l_{2} / l_{1}$

Then the shape parameter $\alpha$ is estimated with $l_{1}$ and $l_{2}$ with equation below by iteration using recursion:

$205 \frac{1}{\sqrt{\pi}} \frac{\Gamma\left(\alpha_{L}+3 / 2\right)}{\Gamma\left(\alpha_{L}+2\right)}=\frac{l_{2}}{l_{1}}$

where $\alpha_{\mathrm{L}}$ is the LM estimate of $\alpha$.

Once the shape parameter is determined, the estimator for the scale parameter is calculated from: 
$\beta_{\mathrm{L}}=\frac{\alpha_{1}+1}{l_{1}}$

The Python programs are designed to estimate the gamma distribution function from the precipitation events with these equations, as well as to estimate extreme precipitation thresholds.

\subsection{Method for spatio-temporal changes}

Mann-Kendall non-parametric test (M-K test) is a statistical test widely used to detect monotonic trends in climatological data series. Two advantages of M-K test were summed up by Soro et al (Soro et al., 2016):

- Distribution-free. It does not need to assume any distribution function of the values.

- Low sensitivity to abrupt breaks in homogeneous time series. It does not need to censor missing data.

Precipitations are intermittent and highly scale-dependent (Sun and Stein, 2015). Therefore, The M-K test is used to analyse the trends of extreme precipitation in seasons.

If $X_{i}$ and $X_{j}$ are the time series precipitation observations in chronological order, then the M-K Statistics $S, V(S)$ and standardized test statistics $Z$ are calculated with equation as follows (Ahmad et al., 2015):

$$
\begin{aligned}
& S=\sum_{i=1}^{n-1} \sum_{j=i+1}^{n} \operatorname{sig}\left(X_{j}-X_{i}\right) \\
& \operatorname{sgn}\left(X_{j}-X_{i}\right)=\left\{\begin{array}{lr}
+1 & \text { if }\left(X_{j}-X_{i}\right)>0 \\
0 & \text { iif }\left(X_{j}-X_{i}\right)=0 \\
-1 & \text { if }\left(X_{j}-X_{i}\right)<0
\end{array}\right.
\end{aligned}
$$

$V(\mathrm{~S})=\frac{1}{18}\left[\mathrm{n}(n-1)(2 n+5)-\sum_{p=1}^{q} t_{p}\left(t_{p}-1\right)\left(2 t_{p}+5\right)\right]$

$\mathrm{Z}= \begin{cases}\frac{\mathrm{S}-1}{\sqrt{\mathrm{VAR}(\mathrm{S})}} & \text { if } S>0 \\ 0 \quad \text { if } S>0 \\ \frac{\mathrm{S}+1}{\sqrt{\mathrm{VAR}(\mathrm{S})}} & \text { if } S<0\end{cases}$

where $n$ is the length of time series, $t_{p}$ is the number of data points for $p$ th values, and $q$ is the number of tied groups in the data set. When $V(S)>0$, it indicates an upward trend in the precipitation series. When $V(S)<0$, a negative trend. $Z$ value is to detect whether the trend is significant. If $|Z|>Z_{(1-0.5 \times \alpha)}$, there exists a statistically significant trend in the series. $Z_{(1-0.5 \times \alpha)}$ is the critical value for $p$ value of 0.05 from the standard normal table.

225 Spatial distribution of precipitation hazards is analysed with a GIS method. Extreme precipitation is the main disastercausing factor of floods in the study area. The extreme precipitation thresholds of different probabilities are used to evaluate 
the flood risk in each meteorological station. The inverse distance weighted method (IDW) is employed to interpolate and zone the events estimated from the Gamma distribution after validated with observations.

\section{Results and discussion}

\subsection{Frequency and contributions of precipitation events}

Runs of $12-\mathrm{H}$ precipitation in each station were calculated based on the standard of an event with records of precipitation $>0.1 \mathrm{~mm}$ and interval $\leq 12$ hours, with the purpose to keep independent for time series analysis. We further calculated their frequency and contribution to the total precipitation in all the stations and plotted them in Figure 2. Figure 2 showed that the frequency of precipitation events decreased with runs increasing. 1-run continuous precipitation event occurred most frequently, accounting for $39.0 \%$ of the total events; followed by the 2-run, with a frequency of $21.7 \%$. Frequency of events $\leq 4$ runs accounted for as high as $83.5 \%$ of the total events. Frequency of events $\leq 10$ runs reached $98.6 \%$. Events greater than 10 runs only accounted for $1.4 \%$ of the total. This indicated that the study area was mainly characterized with short duration precipitation events. Events of 1 to 4 runs occurred most commonly (frequency>10\%). Events greater than 10 runs occurred rarely. The longest consecutive event was the 28-run, which only occurred once at Jgs station in June 1994.

240 Figure 2 also shows that the contribution of runs of precipitation events to the total precipitation rose slowly first and then fell sharply. Contributions gradually increased from $9.5 \%$ to $16.3 \%$ from 1-run events to the 3-run. 3-run precipitation events contributed the most to the total precipitation. Contribution of events $>14$ runs decreased to less than 1\%; Cumulative contributions of events with 1-10run counted for $92.6 \%$ while events greater than 10 runs only $7.4 \%$. This indicates that continuous precipitation events that contributed the most to total precipitation were events of 1-5 runs (Their contribution rates were all $>10 \%$ ). The precipitation events with a longer duration had lower frequency and contributed fewer to the total precipitation.

Frequency and contribution to total precipitation of all the runs in the study area were not proportional according to Figure 2. Frequency of 1-run and 2-run events was higher than their contribution rates. Contribution rates of events $>3$ runs were all greater than their frequency. Frequency of the 1-run precipitation event (Its frequency was 39\% and contribution was 9.5\%) was 2.61 times bigger than that of the 3-run (Its frequency was $14.9 \%$ and contribution was $16.3 \%$ ), but the contribution rate of the former was only $58 \%$ of the latter events. This indicated that precipitation events fewer than 3 runs occurred most often but the total amount was small. 3-run precipitation events contributed the most precipitation with lower frequency and would be key events for flood monitoring.

Figure 3 reported the cumulative probability distribution and fitted gamma curves in stations. Consecutive events fewer than

25510 runs showed an abrupt rainfall rise, up to more than $250 \mathrm{~mm}$ in all the stations. Rainfall of runs longer than 10 roses slowly, with increasing rainfall less than $30 \mathrm{~mm}$ in most stations. This result showed the similar findings to the analysis about Figure 2, that is, precipitation events with very long duration occurred rarely and had minimal contribution to the total. Therefore 1 to 10 runs were selected as experimental data for estimating flood risk in the follow-up analysis. 


\subsection{Gamma fits of precipitation events}

\subsubsection{Estimated distribution of precipitation events}

As presented in Section 3.3, gamma function was used to fit observed precipitation data first with the purpose to give a uniformly rigorous and systematic approach. Table 2 showed the mean values of $\alpha$ and $\beta$ of the gamma curves in the four seasons. The shape parameter $\alpha$ was $\leq 1$ in all the cases, indicating that events with small amounts of rainfall account for a substantial large proportion while events with large amounts of rainfall account for very small proportion. This case is common for the four seasons, especially in summer and autumn when $\alpha$ is $\leq 0.1$, indicating that these two seasons are characterized with occasional and sudden extreme heavy precipitation. The scale parameter $\beta$ has a greater temporal variability. $\beta$ in summer is the bigger, followed by that in spring, autumn and winter. The higher values of $\beta$ in spring are from $\mathrm{Nd}$ and $\mathrm{Ln}$. These two stations are located in the mountainous areas in the upstream where northerly cold air meet with warm air from the ocean in spring, often resulting in frontal and cyclone precipitation. The higher values of $\beta$ in summer appear in Nc, Zs and Yof, which are located in the alluvial plains where the precipitations are often caused by typhoons heading west and southwest in summer (Yin, Kim et al. 2007). The higher values of $\beta$ in autumn are in Sc, Yof, Nd and Ln, indicating that fronts, typhoons and other air activities are frequent in autumn and the main precipitation occurs in the hilly area of the upper Ganjiang river.

\subsubsection{Changing trends of the gamma parameters}

Temporal trends of the shape parameter $\alpha$ and the scale parameter $\beta$ were further analysed with the Mann-Kendall. Table 3 summarized the results, which indicated that precipitation would occur more occasionally with higher intensity in spring, winter and autumn. The two parameters in most stations are experiencing more intensive changes in spring. $\alpha$ in spring show a significant downward trend in Yf, Yc, Jgs, Sc, Nc, Zs and Nd with the absolute value of Z bigger than 2.32 while $\beta$ exhibits

280 a upward trend in Yf, Lh, Zs, Nd and Ln. The trend of $\alpha$ are tested downward in Jgs, Yof and Ln in autumn while the trend of $\beta$ are upward in Ja, Zs and Yof. $\beta$ in Ja, Jgs, Sc, Gx, Yof and Nd show an upward trend in winters. No obvious trends are detected in summer. Studies show that decreases of the shape parameter $\alpha$ will lead to decreases of the extreme precipitation threshold, which in turn increases the risk of storm floods (Rodrigo, 2010). The down-trend $\alpha$ along with upward-trend scale parameter $\beta$ in Yf, Zs, Nd means that the intensity and occasional probability of concentrated precipitation events in these stations will increase in the future, which will thereby increase the risk of storm floods in spring. Similar cases were also found in Yof in autumn and Jgs in winter, which indicated that extreme precipitation would become more intensive with warmer and warmer climate. The particular case is the station of Jgs, with $\alpha$ decreasing in all the seasons except summer. Jgs is located on the mountain with elevation of $843 \mathrm{~m}$. We may infer this mountainous station will present increasingly obvious maritime precipitation characteristics in the future. 


\subsection{Risk of extreme precipitation}

\subsubsection{Estimation of thresholds for extreme precipitation}

The $99 \%$ percentiles and their estimates obtained from the gamma distribution were calculated as thresholds with $12-\mathrm{H}$ precipitation data first. Table 4 shows the mean values in each station. The estimated threshold values show higher variability from winters to summers in Table 4 . The maximum threshold values occur in summer, followed by spring, autumn and winter. The study area is mainly controlled by monsoons and typhoons in summer, which result in the most concentrated heavy precipitation (Shan, Zhang et al. 2001). In spring the ridge of the subtropical high system moved to the south of $20^{\circ} \mathrm{N}$ latitude. The warm and humid air from the south along the subtropical high ridge intersects cold air from the north, forming fronts and cyclones activities which bring a wide range of cloudy and rainy weather. Autumn and winter are often affected by the winter monsoon which is characterized with cold air and low precipitation (Zhang and Song 2018).

What stands out in Table 4 is that the estimated gamma values are $0.3-0.8 \%$ lower than those from the observed on average, with the smallest in spring $(0.3 \%)$ and the largest in autumn $(0.8 \%)$. This result is similar to that from in literature (Rodrigo 2010). A slightly lower threshold of extreme precipitation will increase flood risks, which allows risk managers to improve risk management before storm floods occur. Thereby the lower values from the Gamma function would help reduce risks. The 99th percentiles estimates are maintained as the threshold values to obtain the risk analysis.

The estimated thresholds of 12 hours to 120 hours' precipitations events (1 to 10 runs of $12-\mathrm{H}$ events) were also calculated and plotted. The Kolmogorov-Smirnov test (KS ) was used to test the goodness of the fits at the 95\% confidence level. KS values rang from 0.06 to 0.12 , which show that Gamma distribution had a good agreement with the selected thresholds from the observations. Forty-eight fits (4 seasons $\times 12$ stations) were calculated eventually and Figure 4 shows an example in Ganxian Station. Its horizontal axis represents scenarios or probability while the vertical axis represents thresholds of extreme precipitation events in millimeters $(\mathrm{mm})$. The lowest curve is the fit from 1-run observed precipitation. Curves from the 2-run to the 10-run are higher and higher. Figure 4 shows there are bigger intervals between curves in summer and winter, indicating that runs of precipitation events in summer and winter have a greater impact on the extreme event thresholds.

315 Compared with 5 to 10 runs, the intervals are even larger between 1-4 runs, indicating that the precipitation threshold changes greatly when the events happen in 48 hours. The curve slopes in all the four pictures are steep when the probability is less than $0.5(1 / 2)$, which shows precipitation thresholds increase quickly. The slopes gradually declined when the probability is less than $0.2(1 / 5)$. It shows the precipitation threshold increases slowly as the probability decreases. Fits in other stations show similar trend.

320 With the help of these gamma fits, thresholds under any given probability could be estimated. The orange hollow points in Figure 4 shows estimates when the recurrence period is set to be one in 2 years (its probability is 0.5$)$, one in 5 years $(0.2)$, one in 10 years $(0.1)$, one in 20 years $(0.05)$ and one in 50 years $(0.02)$ respectively, which will be used for flood risk analysis later in the following section. 


\subsubsection{Extreme events and floods}

325 The estimated thresholds in Section 4.3.1 could help to analyse extreme precipitation events and their risks. In order to identify what kind of extreme events would cause floods, we selected Ganxian, a meteorological station and Hanlinqiao, a hydrological observation station to do a comparative analysis. Ganxian Station (E115, N25.87), located at the lower reach of the Gongshui River (a branch of the Ganjiang River in its upper reach), is a national meteorological observatory. It is one of the four national basic stations in the upper reach of the Ganjiang River. The records in Ganxian began in 1951 and are relatively complete with good data consistency. Hanlinqiao is a regional representative hydrological station at E115 $12^{\prime}$, N26 $03^{\prime}$. It was established in February 1953 and located in Laoheshi Village, Jibu Town, Ganxian County, downstream of the Pingiiang River whose catchment area is $2689 \mathrm{~km}^{2}$. It is 17 kilometres away from the entrance to The Gongshui River. The two stations are close and the representative area covers almost the same region.

The extreme events supposed to be with risk to cause floods in Ganxian are selected according to the following standards

335 and Table 5 shows number of selected events:

1) Events above thresholds estimated by the Gamma curves of 1-10 runs in Section 4.3.1;

2) Events under the scenarios of probability at $0.5,0.2,0.1,0.05$ and 0.02 , representing return periods of 2, 5, 10, 20 and 50 years respectively.

3) The time intervals between two events are greater than one run (12 hours).

340 4) Events between 2009-2014, which is the period of the collected hydrological data.

The floods events in Hanlinqiao is selected according to the standards below and Table 6 shows the result:

1) Events above the threshold which is the $99 \%$ percentiles of the daily flow records

2) The time interval between two events greater than one day, that is, the estimated convergence time from the farthest point to the outlet in the catchment.

345 Analysis from Table 5 and Table 6 shows that the predicted extreme precipitation events have the similar trends as the flood records. Both of them have more events in spring than those in summer, followed by autumn and winter. Table 5 shows the predicted events of all the runs in spring account for more than 40 percent under the scenarios of probability at $0.5,0.2,0.1$, and about 30 percent under scenarios of probability at 0.05 and 0.02 . Events in summer account for more than 30 percent under all the scenarios. Those in autumn and winter only account for 20 percent or so from 2009 to 2014. Flood records in Hanlinqiao find 12 events in the 6 years. Seven events are in spring and 5 in summer. No events are found in autumn and winter. Compared with flood records, thresholds in Scenario 1 (probability at 0.5 ) is a little low which will overestimate extreme precipitation events. Scenarios 3, 4 and 5 (probabilities at 0.1, 0.05 and 0.02) have high thresholds which will underestimate the events. The predicted extreme precipitation events from Scenario 2 (probability at 0.2 ) are very close to the recorded flood events.

355 Of all the runs under Scenario 2, predicted events from runs more than 7 are lower than the recorded floods. It is acomplex process from precipitations to floods, involving several disaster-generating environments such as land covers, topography, 
soil, temperature, shape of the catchment area, etc. It is reasonable that the predicted extreme precipitation events are bigger than or equal to flood events in flood risk assessment. Therefore, Runs 1, 2, 3, 4, 5 and 6 are more suitable to predict extreme events. According to the flood events at Hanlinqiao Station, the predicted events from Run 1 (one 12-H precipitation) under Scenario 1 are almost double of the floods records. Events from Runs 2,3,4,5 and 6 are all more or very close to the floods records. The analysis indicates that events predicted from precipitation of 12-72 hours are all very helpful for flood estimates while those from more than 72 hours, which will underestimate the flooding risk, have little use in flood prediction. There are some cases that small precipitation (small than the given threshold) was observed at the beginning, which was not considered to cause floods. However, a new record of precipitation that is just above the threshold in the following periods eventually led to flooding because of rainfall accumulated in the previous period. If time intervals of precipitation are too long, this flood event will be missed because of the high threshold. Run 1 (12-H precipitation) will be the best time intervals for predicting extreme events in flood risk, which will avoid such missed cases.

\subsubsection{Spatial analysis of flood risk caused by extreme events}

The paper further analysed the overall flood risk caused by extreme precipitation events in the study area. The method was listed below according to the analysis above.

1) The observed precipitation was $12-\mathrm{H}$ precipitation from the 12 meteorological stations. The 99th percentile of the cumulative frequency distribution was used for selecting thresholds in each season.

2) A gamma function was used to fit the observed data. Thresholds were calculated at a given probability of 0.2 from the gamma curves. Events bigger than the threshold were considered as the extreme precipitation events.

375 3) The number of events in all the station was further interpolated with an inverse distance method. The results were stretched from low to high according to number of the events.

Maps of flood risk map in spring, summer, autumn and summer with the methods above are followed in Figure 6 to show spatial analysis of flood risk caused by extreme events. Figure 6 shows that the high-risk centres of extreme precipitation are distributed on the east side of the Luoxiao Mountains in the west in spring, moving south to the upper reaches of the

380 Ganjiang River which is the north side of the Nanling Ranges in summer. Two new high-risk centres are formed in the middle reaches of Ganjiang River, near the west side of Wuyi Mountain in autumn and tend to move eastward and northward in winter. The low-risk areas are distributed in the Jitai Basin which is in the middle reaches of the Ganjiang River and the upper Ganzhou Basin in spring, moving north to the lower reaches to the Poyanghu Lake in summer, then moving slightly to the south in autumn. In winter a new low-risk centre is formed in the northwest, and move to the northwest and the northwest near the Luoxiao Mountain in the west. In general, the extreme precipitation has a high risk of flooding in the upper reaches of the Ganjiang River, the Jitai Basin in the middle reaches and the northern plains. Risks are positively correlated with elevation in the northern river-lake plain area and the Jitai Basin in the midstream area while risks in the southern hilly area are the opposite, negatively correlated with elevation. This risk result is similar to the conclusions of the literature Yin et al. (YIN, TIAN et al. 2018). 
390 The main weather systems that cause extreme precipitation in the study area include low- and medium-level shear lines, lowlevel jets, typhoon low pressure, etc (Shan, Zhang et al. 2001). Monsoons in spring and summer from the tropical ocean run southwest in the study area, are uplifted with micro-topography and result in high-risk centres in the west and south mountain region. The winter monsoons in autumn and winter from deep inland move southeastward and form frontal precipitation when they encounter stranded warm air currents, causing high-risk centres in the eastern and southern parts in the study area.

\subsection{Discussion}

\subsubsection{Time scales of precipitation}

Precipitation events, especially high intensity precipitation events, are key to precipitation is highly variable in time (Beck et al., 2015) and intermittency is a core characteristic (Trenberth et al., 2017). This paper investigated the time scales of precipitation with $12-\mathrm{H}$ data and found the frequency of precipitation events has a significant negative correlation with the duration of precipitation, which showed that the study area was mainly characterized with short duration precipitation events and events greater than 10 runs occurred very rarely. Hence short duration precipitation events would be a key hazard factor for extreme precipitation forecasting, flood and disaster risk management analysis. Researches shows that global warming, urban built-up areas and nearby suburbs, condensate and cloud base elevations in rural and wilderness areas may lead to a decrease in the frequency of short duration precipitation events. Cheng et al. investigate the precipitation Intensity-DurationFrequency (IDF) in a changing climate and find that climate-induced changes on heavy rainfall events are non-uniform. The shorter precipitation events have been changed more in the past decades, while longer events have not changed substantially (Cheng and Aghakouchak, 2014). Hosseinzadehtalaei et al. find the frequency of sub-daily extreme precipitation events of 50- and 100-year return periods will be tripled under the high-end RCP8.5 scenario in the future climate change, which will increased the risk of the existing water infrastructure systems(Hosseinzadehtalaei et al., 2020). Similar cases are also found in China. Ren at al. analysed the data from 2,300 stations across China. Their research shows that the frequency of trace precipitation (precipitation with a daily rainfall of less than $0.1 \mathrm{~mm}$ ) has shown a more significant downward trend than the frequency of light rain events in the eastern monsoon region. The frequency of light precipitation in the eastern monsoon region has shown a very obvious downward trend (

415 the east Asian monsoon region. Changes in short-duration precipitation events caused by climate warming will cause higher risk of flooding, which are certainly the key indicator for further study on climate change, floods and other extreme weather disasters.

\subsubsection{Extreme precipitation and Flood risk}

In fact, most precipitation events bring us necessary beneficial freshwater resources. Only few events, especially extreme 
must consider how extreme precipitation is defined and choose the data for their extreme precipitation analysis with care (Pendergrass, 2018). We compared the extreme precipitation events estimated with 1-10 runs of 12-H data with the flood records in hydrological observation station. We found that the number of events from 1, 2, 3 and 4 runs of 12-H data were relatively close to that of flood records and the number of diagnosed extreme events decrease as the accumulated precipitation time increases. Similar case are also found in the research of Merino et al. (Merino, Fernández-González et al. 2018), who select 29 floods in rivers between 2000 and 2014 in Spain and compare their extreme precipitation events from hourly precipitation data with those from daily accumulated precipitation to find their capability identifying major flood events. The result show that no extreme precipitation events are identified in eight of the flood events using definition based on daily precipitation but events based on sub-daily data permit much more accurate identification of events posing hydrologic risks (Merino et al., 2018). Obviously it would be better to use sub-daily precipitation for extremely events analysis to avoid underestimation potentially dramatic consequences they caused like flood risk. In practice, daily precipitation series are commonly used to analyse extreme precipitation events with their sufficient quantities and few homogeneity problems because high time resolution precipitation data are not provided or recorded in most regions. Remotely sensed data from satellites or rain radar would be suitable substitute for high spatial resolution sub-daily precipitation analysis (Müller and Kaspar, 2014).

\section{Conclusion}

In this study we investigated the frequency and contributions of precipitation events using sub-daily records in meteorological stations in the Ganjiang river basin; identified their changes and time scales using gamma distribution and M$\mathrm{K}$ test; and explored the definition, thresholds of extreme precipitation events and their risk causing floods. We further spatially mapped flood risk across the entire study domain and analysed the distribution characteristics. Based on the analyses presented in this study, the following main conclusions can be drawn:

(1) Precipitation events with very long duration occurred rarely and had minimal contribution to the total precipitation. The study area was mainly characterized with short duration precipitation events. 3-run (36 hours) precipitation events contributed the most precipitation but with lower frequency.

445 (2) This study has identified by Gamma parameters analysis that extreme precipitations have the characteristics of occasional and sudden occurrence in summer and spring. The scale parameters $\beta$ presents a trend of summer $>$ spring $>$ autumn $>$ winter. The highest $\beta$ values in spring were identified in mountainous stations such as Ningdu and Longnan. Stations of Nanchang, Zhangshu, and Yongfeng which are in the transition areas from mountains to plains. In autumn, the high values of $\beta$ were found in Suichuan, Yongfeng, Ningdu and Longnan. Temporal trends analysis of $\alpha$ and $\beta$ shows the intensity and occasional probability of precipitation events will increase in spring in the future in Yifeng, Zhangshu and Ningdu, which will in turn increase the risk of storm floods. 
https://doi.org/10.5194/nhess-2021-412

Preprint. Discussion started: 23 February 2022

(c) Author(s) 2022. CC BY 4.0 License.

(3) Risks are positively correlated with elevation in the northern river-lake plain area and the Jitai Basin in the midstream area while risks in the southern hilly area were the opposite, negatively correlated with elevation. Elevation and weather systems such as medium-to-low--level shear lines, low-level jet, the southward route of typhoons are the key disasterpregnant factors for flood risk management.

Author contribution: Liu Guangxu and Wan Zhiwei designed the structures and prepared the manuscript. Xiang Aicun and Lin Sichen collected and processed data. Zhou Yang, Wu Jie and Wang Yuandong revised and improved the manuscript.

Competing interests: The authors declare that they have no conflict of interest.

Acknowledgements: We would like to thank the funding from the Social science Planning project of Jiangxi Province (19GL30), Humanities and Social Science Research Planning Project for Universities of Jiangxi Province (No. GL20116), Science and Technology Project of Jiangxi Department of Education (No. GL20116) and the Natural Science Foundation of China (NSFC) (No. 42161019).

\section{Reference}

Ahmad, I., Tang, D., Wang, T., Wang, M., and Wagan, B.: Precipitation trends over time using Mann-Kendall and spearman's rho tests in swat river basin, Pakistan, Advances in Meteorology, 2015, 2015.

Bao, J., Sherwood, S. C., Alexander, L. V., and Evans, J. P.: Future increases in extreme precipitation exceed observed scaling rates, Nature Climate Change, 7, 128-132, 2017.

Beck, F., Bárdossy, A., Seidel, J., Müller, T., Sanchis, E. F., and Hauser, A.: Statistical analysis of sub-daily precipitation extremes in Singapore, Journal of Hydrology: Regional Studies, 3, 337-358, 2015.

Cheng, L. and AghaKouchak, A.: Nonstationary precipitation intensity-duration-frequency curves for infrastructure design in a changing climate, Scientific reports, 4, 1-6, 2014.

Easterling, D. R., Alexander, L. V., Mokssit, A., and Detemmerman, V.: CCI/CLIVAR workshop to develop priority climate indices, Bulletin of the American Meteorological Society, 84, 1403-1407, 2003.

Easterling, D. R., Meehl, G. A., Parmesan, C., Changnon, S. A., Karl, T. R., and Mearns, L. O.: Climate extremes: observations, modeling, and impacts, Science, 289, 2068-2074, 2000.

El Adlouni, S. and Ouarda, T.: Frequency analysis of extreme rainfall events, Rainfall: State of the science, 191, 171-188, 2010.

7.20 Zhengzhou Extraordinary Heavy Storm: https://baike.baidu.com/item/7\%C2\%B720\%E9\%83\%91\%E5\%B7\%9E\%E7\%89\%B9\%E5\%A4\%A7\%E6\%9A\%B4 $\% \mathrm{E} 9 \% 9 \mathrm{~B} \% \mathrm{~A} 878654 \mathrm{r} 86$, last

Gao, T. and Xie, L. a.: Study on progress of the trends and physical causes of extreme precipitation in China during the last 50 years (in Chinese), Advances in Earth Science, 29, 577, 2014.

Gao, T., Wang, H. J., and Zhou, T.: Changes of extreme precipitation and nonlinear influence of climate variables over monsoon region in China, Atmospheric research, 197, 379-389, 2017.

Haylock, M. and Nicholls, N.: Trends in extreme rainfall indices for an updated high quality data set for Australia, 19101998, International Journal of Climatology: A Journal of the Royal Meteorological Society, 20, 1533-1541, 2000.

Hosking, J. R.: L-moments: Analysis and estimation of distributions using linear combinations of order statistics, Journal of the Royal Statistical Society: Series B (Methodological), 52, 105-124, 1990.

Hosseinzadehtalaei, P., Tabari, H., and Willems, P.: Climate change impact on short-duration extreme precipitation and intensity-duration-frequency curves over Europe, Journal of hydrology, 590, 125249, 2020. 
https://doi.org/10.5194/nhess-2021-412

Preprint. Discussion started: 23 February 2022

(c) Author(s) 2022. CC BY 4.0 License.

Hu, Q., Yang, D., Wang, Y., and Yang, H.: Accuracy and spatio-temporal variation of high resolution satellite rainfall estimate over the Ganjiang River Basin, Science China Technological Sciences, 56, 853-865, 2013.

Kliche, D. V., Smith, P. L., and Johnson, R. W.: L-moment estimators as applied to gamma drop size distributions, Journal of applied meteorology and climatology, 47, 3117-3130, 2008.

Li, N., Tang, G., Zhao, P., Hong, Y., Gou, Y., and Yang, K.: Statistical assessment and hydrological utility of the latest multi-satellite precipitation analysis IMERG in Ganjiang River basin, Atmospheric research, 183, 212-223, 2017.

LIU, X., FAN, S., WANG, J., and XU, C.: Analysis on Meteorological Characteristics of a Strong Storm Disasters in the Eastern Foot of Longmen Mountain, Journal of Catastrophology, 33, 102-110, 10.3969/j.issn.1000811X.2018.01.019, 2018.

Müller, M. and Kaspar, M.: Event-adjusted evaluation of weather and climate extremes, Natural Hazards and Earth System Sciences, 14, 473-483, 2014.

Merino, A., Fernández-González, S., García-Ortega, E., Sánchez, J., López, L., and Gascón, E.: Temporal continuity of extreme precipitation events using sub-daily precipitation: application to floods in the Ebro basin, northeastern Spain, International Journal of Climatology, 38, 1877-1892, 2018.

Mukherjee, S., Aadhar, S., Stone, D., and Mishra, V.: Increase in extreme precipitation events under anthropogenic warming in India, Weather and climate extremes, 20, 45-53, 2018.

Pachauri, R. K., Allen, M. R., Barros, V. R., Broome, J., Cramer, W., Christ, R., Church, J. A., Clarke, L., Dahe, Q., and Dasgupta, P.: Climate change 2014: synthesis report. Contribution of Working Groups I, II and III to the fifth assessment report of the Intergovernmental Panel on Climate Change, IPCC, Geneva, Switzerland, 151 pp.2014.

Papalexiou, S., Koutsoyiannis, D., and Makropoulos, C.: How extreme is extreme? An assessment of daily rainfall distribution tails, Hydrology and Earth System Sciences, 17, 851-862, 2013.

Pendergrass, A. G.: What precipitation is extreme?, Science, 360, 1072-1073, 2018.

Pfahl, S., O'Gorman, P. A., and Fischer, E. M.: Understanding the regional pattern of projected future changes in extreme precipitation, Nature Climate Change, 7, 423-427, 2017.

Rodrigo, F.: Changes in the probability of extreme daily precipitation observed from 1951 to 2002 in the Iberian Peninsula, International Journal of Climatology, 30, 1512-1525, 2010.

Saidi, H., Ciampittiello, M., Dresti, C., and Ghiglieri, G.: Assessment of trends in extreme precipitation events: a case study in Piedmont (North-West Italy), Water Resources Management, 29, 63-80, 2015.

ŞEN, Z. and Eljadid, A. G.: Rainfall distribution function for Libya and rainfall prediction, Hydrological sciences journal, 44, 665-680, 1999.

ShI, P., Kong, F., and Fang, J.: Spatio-temporal Patterns of China Decadal Storm Rainfall (in Chinese), Scientia Geographica Sinica, 34, 1281-1290, https://doi.org/10.13249/j.cnki.sgs.2014.011.1281, 2014.

Soro, G. E., Noufé, D., Goula Bi, T. A., and Shorohou, B.: Trend analysis for extreme rainfall at sub-daily and daily timescales in Côte d'Ivoire, Climate, 4, 37-52, 2016.

Sun, Y. and Stein, M. L.: A stochastic space-time model for intermittent precipitation occurrences, The Annals of Applied Statistics, 9, 2110-2132, 2015.

Tabari, H.: Climate change impact on flood and extreme precipitation increases with water availability, Scientific reports, 10 , $1-10,2020$.

Tabari, H. and Willems, P.: Lagged influence of Atlantic and Pacific climate patterns on European extreme precipitation, Scientific reports, 8, 1-10, 2018.

Talchabhadel, R., Karki, R., Thapa, B. R., Maharjan, M., and Parajuli, B.: Spatio-temporal variability of extreme precipitation in Nepal, International Journal of Climatology, 38, 4296-4313, 2018.

Trenberth, K. E.: Conceptual framework for changes of extremes of the hydrological cycle with climate change, in: Weather and climate extremes, Springer, 327-339, 1999.

535 Trenberth, K. E., Zhang, Y., and Gehne, M.: Intermittency in precipitation: Duration, frequency, intensity, and amounts using hourly data, Journal of Hydrometeorology, 18, 1393-1412, 2017.

Trenberth, K. E., Dai, A., Rasmussen, R. M., and Parsons, D. B.: The changing character of precipitation, Bulletin of the American Meteorological Society, 84, 1205-1218, 2003.

Vivekanandan, N.: Flood frequency analysis using method of moments and L-moments of probability distributions, Cogent engineering, 2, 1018704, 2015. 
Wang, Q.: Direct sample estimators of L moments, Water resources research, 32, 3617-3619, 1996.

Wang, X. L.: Accounting for autocorrelation in detecting mean shifts in climate data series using the penalized maximal $t$ or F test, Journal of applied meteorology and climatology, 47, 2423-2444, 2008.

Wang, X. L., Chen, H., Wu, Y., Feng, Y., and Pu, Q.: New techniques for the detection and adjustment of shifts in daily precipitation data series, Journal of applied meteorology and climatology, 49, 2416-2436, 2010.

$\mathrm{Wu}$, J., Zhou, B., and Xu, Y.: RESPONSE OF PRECIPITATION AND ITS EXTREMES OVER CHINA TO WARMING: CMIP5 SIMULATION AND PROJECTION (in Chinese), Chinese Journal of Geophysics, 58, 3048-3060, d o i : $10.6038 /$ c j g $201550903,2015$.

Wu, X., Guo, S., Yin, J., Yang, G., Zhong, Y., and Liu, D.: On the event-based extreme precipitation across China: Time distribution patterns, trends, and return levels, Journal of hydrology, 562, 305-317, 2018.

Xiao, C., Wu, P., Zhang, L., and Song, L.: Robust increase in extreme summer rainfall intensity during the past four decades observed in China, Scientific reports, 6, 1-9, 2016.

Zeng, Y. and Lu, E.: Changes of Summer Rainfall and Extreme Precipitation During 1961-2010 in China (in Chinese), Climate Change Research, 11, 79-85, doi: 10.3969/j.issn.1673-1719.2015.02.001, 2015.

555 Zhao, Y., Xiao, D., and Bai, H.: Projection and Application for Future Climate in China by CMIP5 Climate Model (in Chinese), Meteorological Science and Technology, 47, 608-621, 2019. 
https://doi.org/10.5194/nhess-2021-412

Preprint. Discussion started: 23 February 2022

(c) Author(s) 2022. CC BY 4.0 License. Natural Hazards
and Earth System
Sciences

Discussions

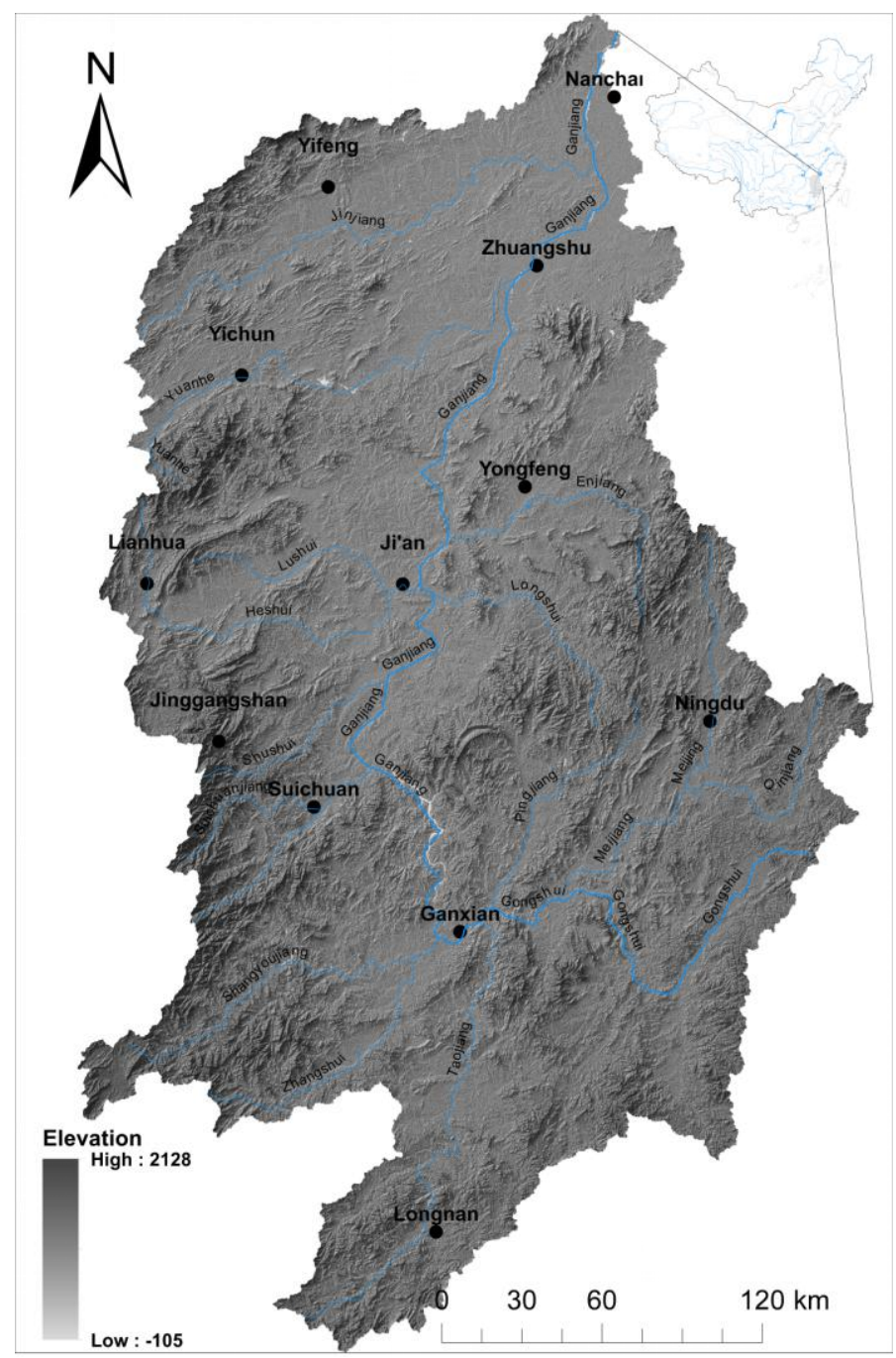

Figure 1 Study area and location of the meteorological stations 


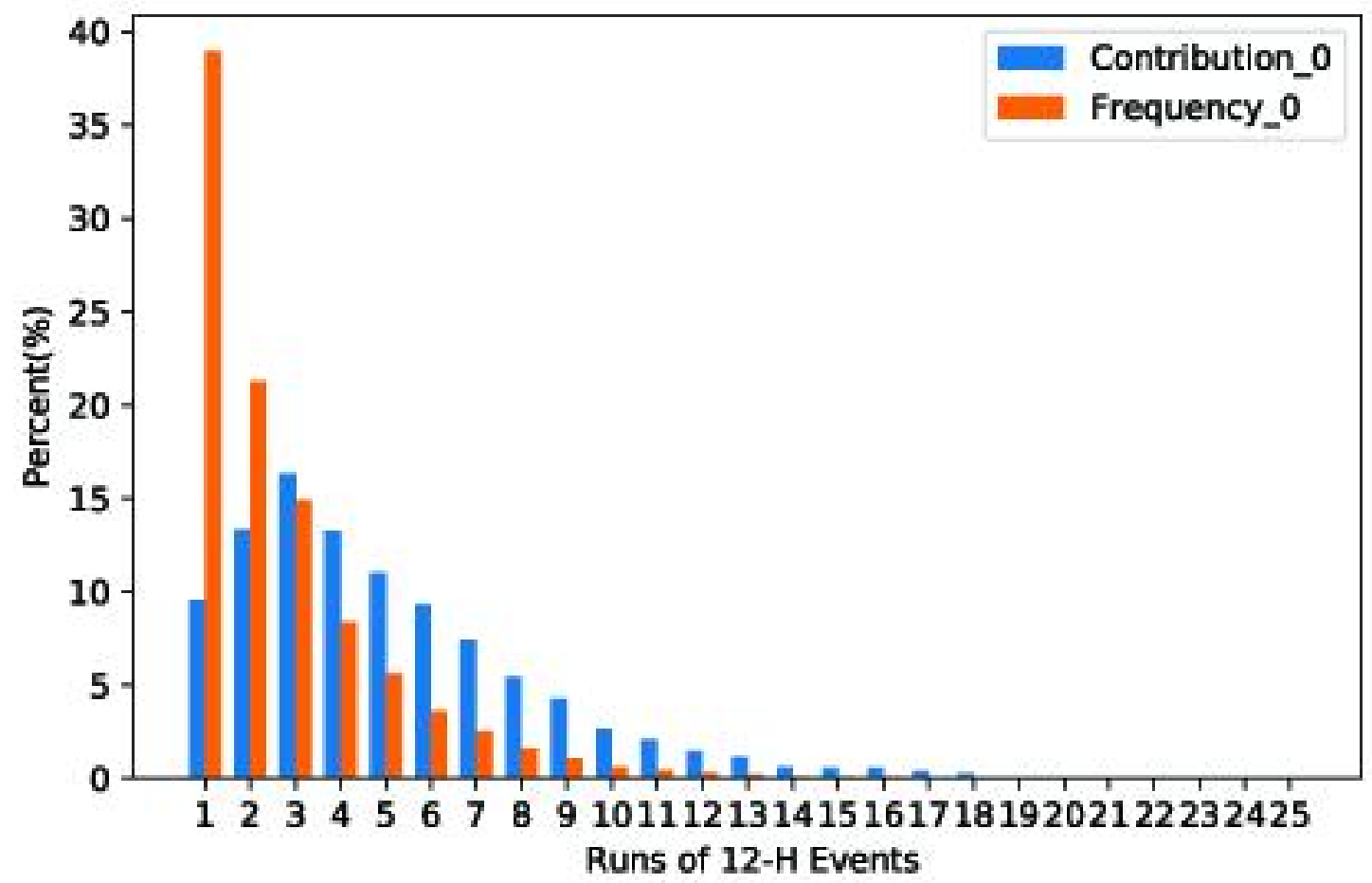

Figure 2 Frequency and contribution of runs of $12-\mathrm{H}$ events 
https://doi.org/10.5194/nhess-2021-412

Preprint. Discussion started: 23 February 2022

(c) Author(s) 2022. CC BY 4.0 License.

(c) (i)

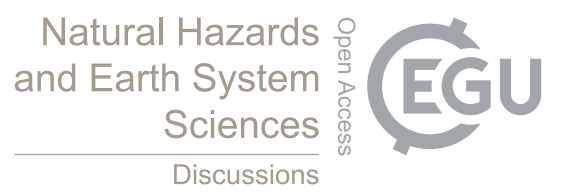

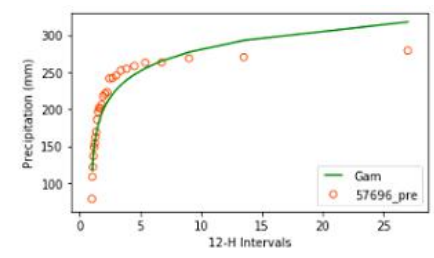
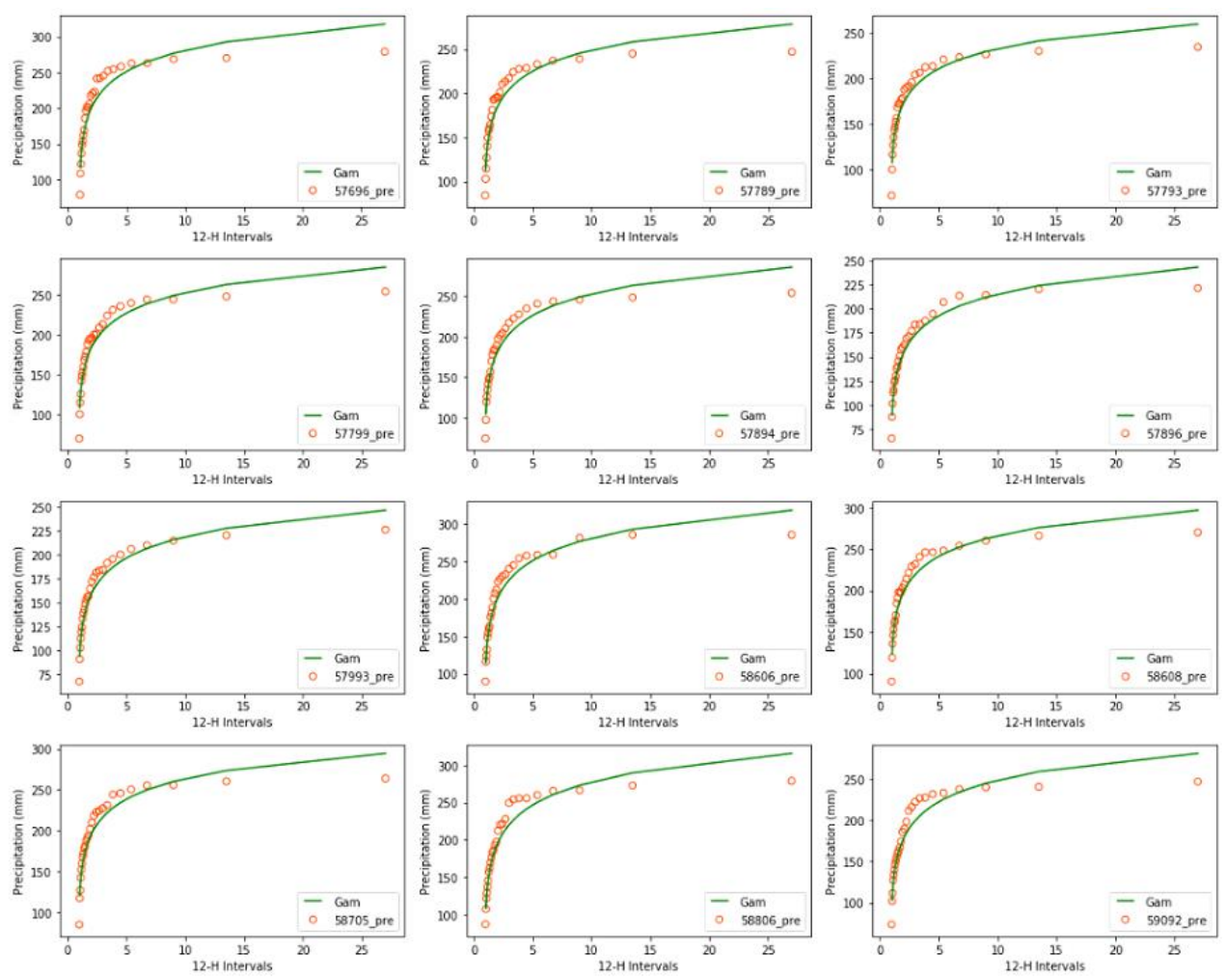

Figure 3 Cumulative precipitation of runs of events. The orange hollow points are observed precipitation events. The green lines are their gamma estimates 
https://doi.org/10.5194/nhess-2021-412

Preprint. Discussion started: 23 February 2022

(c) Author(s) 2022. CC BY 4.0 License.

(c) (i)
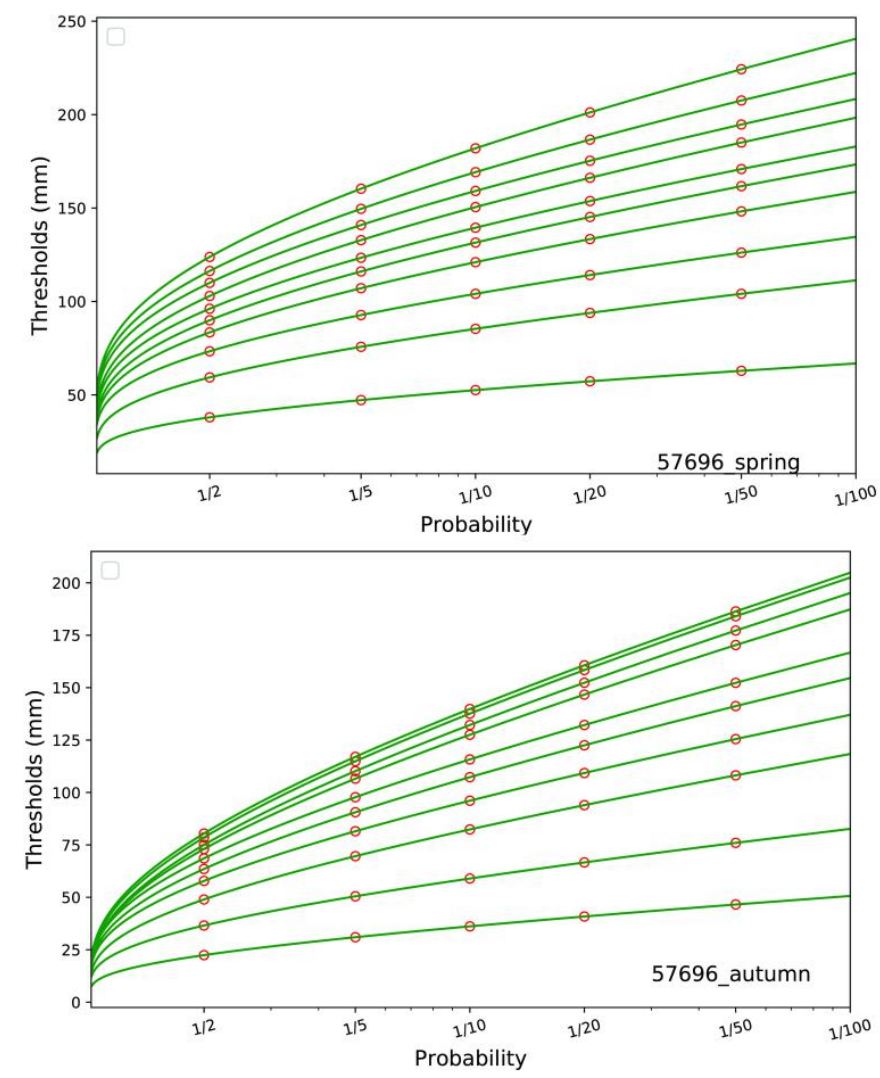
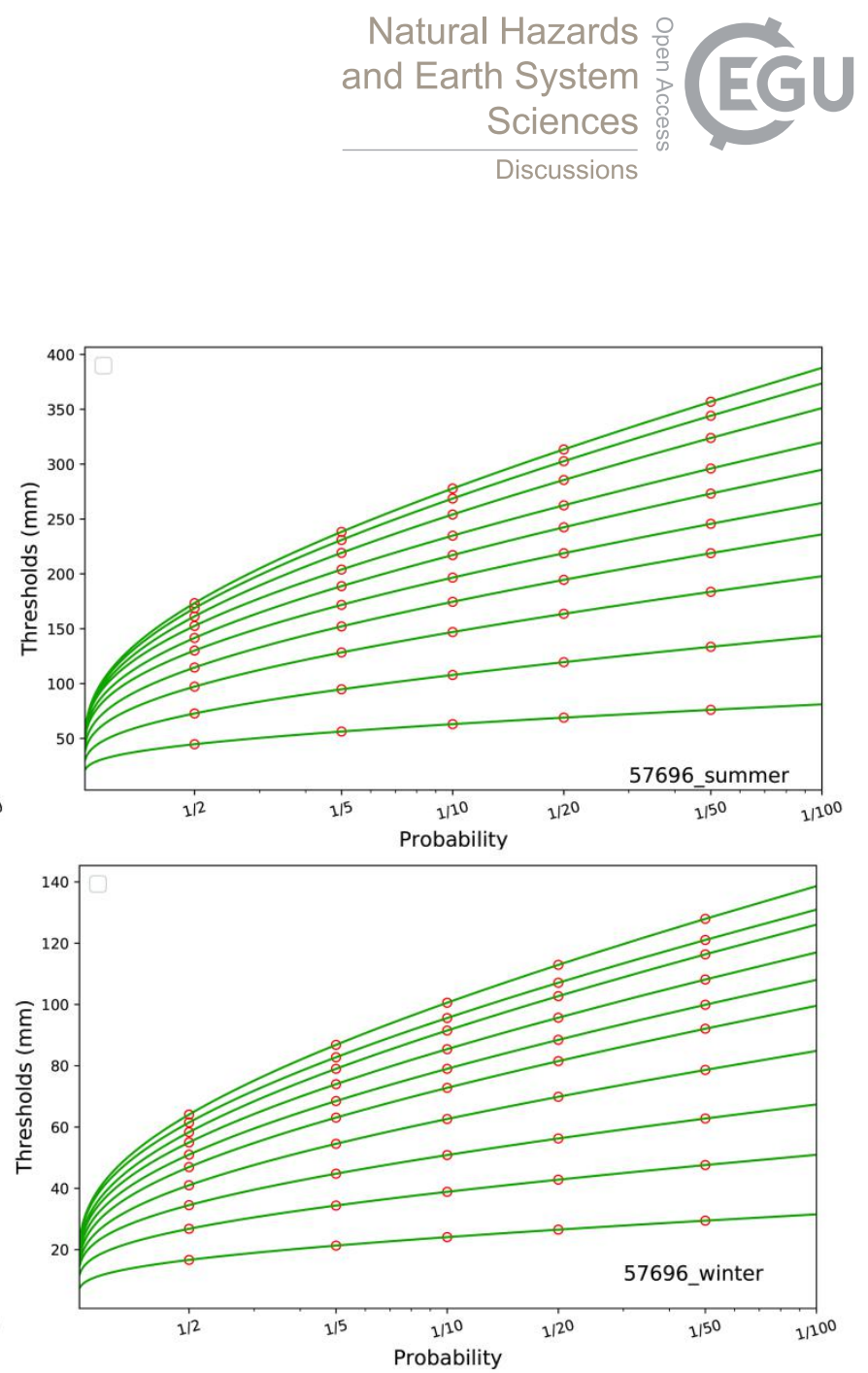

Figure 4 An example of extreme precipitation threshold distribution from the gamma fits of 1-10 run 12-H data in seasons. The green lines from bottom to up show the gamma fits of 1-10 runs respectively. The orange hollow points are thresholds calculated with probability at $0.5(1 / 2), 0.2(1 / 5), 0.1(1 / 10), 0.05(1 / 20)$ and $0.02(1 / 50)$. 
https://doi.org/10.5194/nhess-2021-412

Preprint. Discussion started: 23 February 2022

(c) Author(s) 2022. CC BY 4.0 License.

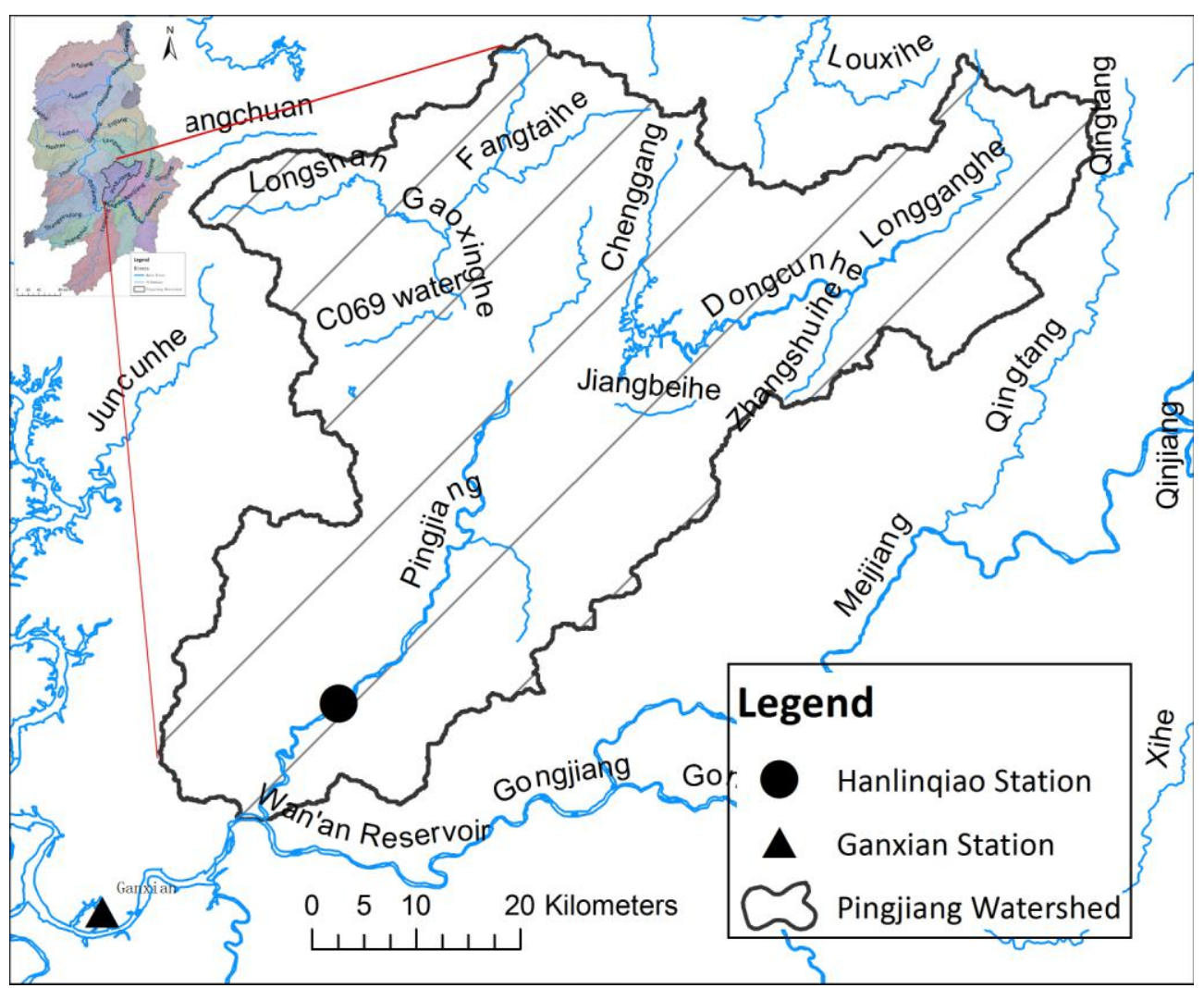

Figure 5 Location of Ganxian meteorological station and Hanlinqiao hydrological observation station 
https://doi.org/10.5194/nhess-2021-412

Preprint. Discussion started: 23 February 2022

(c) Author(s) 2022. CC BY 4.0 License.

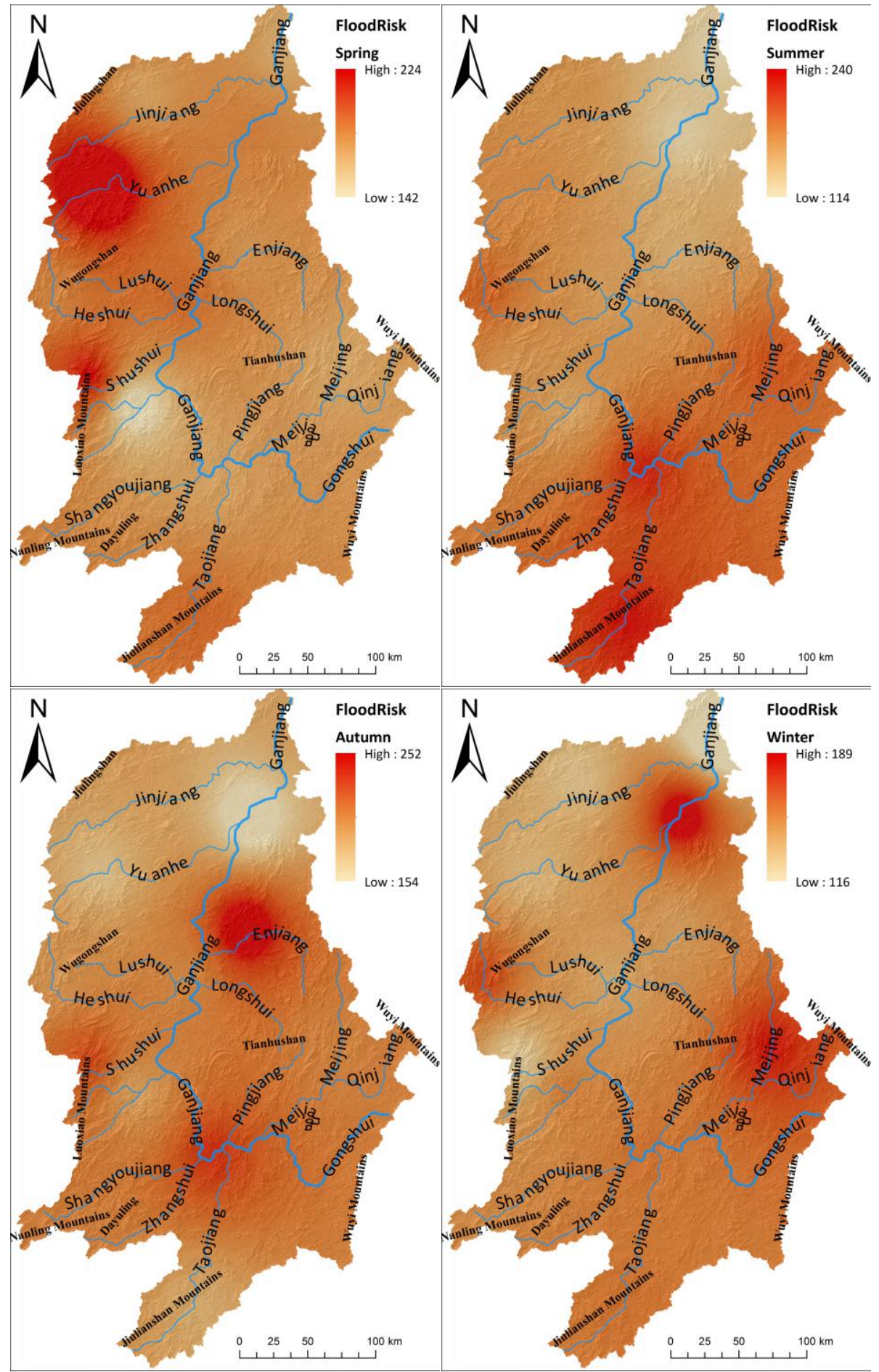

Figure 6 Flood risk under Scenario 2 in spring, summer, autumn and winter in the Ganjiang River basin. The colors range from 
Table 1 Characteristic of meteorological stations

\begin{tabular}{lllll}
\hline \multicolumn{1}{c}{ Stations } & \multicolumn{2}{l}{ Location } & $\begin{array}{c}\text { Elevation } \\
\text { (m a.s.l) }\end{array}$ & $\begin{array}{l}\text { Observation } \\
\text { period (Year) }\end{array}$ \\
\cline { 2 - 3 } & Latitude (N) & Longitude (E) & 47 & $1956-2016$ \\
\hline Nanchang(Nc) & 28.60 & 115.92 & 92 & $1951-2016$ \\
Yifeng (Yf) & 28.40 & 114.78 & 30 & $1951-2016$ \\
Zhangshu (Zs) & 28.07 & 115.55 & 131 & $1956-2016$ \\
Yichun (Yc) & 27.80 & 114.38 & 86 & $1959-2016$ \\
Yongfeng (Yof) & 27.33 & 115.42 & 195 & $1951-2016$ \\
Lianhua (Lh) & 27.13 & 113.95 & 71 & $1956-2016$ \\
Ji'an (Ja) & 27.05 & 114.92 & 843 & $1959-2016$ \\
Jinggangshan (Jgs) & 26.58 & 114.17 & 209 & $1952-2016$ \\
Ningdu (Nd) & 26.48 & 116.02 & 126 & $1957-2016$ \\
Suichuan (Sc) & 26.33 & 114.50 & 138 & $1958-2016$ \\
Ganxian (Gx) & 25.87 & 115.00 & 250 & $1951-2016$ \\
Longnan (Ln) & 24.87 & 114.80 & & \\
\hline
\end{tabular}

Table 2 Mean parameters $\alpha$ (shape) and $\beta$ (scale, $\mathrm{mm} / \mathrm{day}$ ) for gamma distribution in stations

\begin{tabular}{|c|c|c|c|c|c|c|}
\hline \multirow{2}{*}{ ations } & \multicolumn{6}{|c|}{ spring summer autumn winter } \\
\hline & $\alpha \quad \beta$ & $\alpha \quad \beta$ & $\alpha$ & $\beta$ & & $\beta$ \\
\hline If & 0.1623 .43 & 30.0838 .73 & 30.06 & 622.5 & 1 & 2.01 \\
\hline $\mathrm{h}$ & 0.1622 .41 & 00.0835 .95 & $50.0^{7}$ & 71 & 50.1 & 211.29 \\
\hline Yc & 0.1621 .7 & 00.0833 .79 & $0.0^{7}$ & 719 & & 211.79 \\
\hline $\mathrm{a}$ & 0.1522 .1 & 50.0738 .35 & 50.06 & 622 & 00 & 12.21 \\
\hline Igs & 0.1817 .68 & 80.1529 .53 & 30.05 & 92 & & 39.29 \\
\hline $\mathrm{c}$ & 0.1518 & 00.0930 & 30.06 & 62 & & 10.89 \\
\hline Gx & 0.142 & 00.083 & 50 & & & 35 \\
\hline $\mathrm{Nc}$ & 0.1424 .7 & 60.0745 .94 & 40.05 & 524 & & 13.55 \\
\hline$Z s$ & 0.1524 .5 & 80.0743 .46 & 50.06 & 622 & 0.1 & 3.59 \\
\hline Yof & 0.1523 .4 & 00.0839 .48 & 30.06 & 625 & 10. & 12.90 \\
\hline $\mathrm{Nd}$ & 0.1526 .3 & 20.0937 .44 & 40.05 & 526.2 & 40.0 & 9 13.96 \\
\hline
\end{tabular}


https://doi.org/10.5194/nhess-2021-412

Preprint. Discussion started: 23 February 2022

(c) Author(s) 2022. CC BY 4.0 License.

\section{Ln $\quad 0.1325 .010 .1029 .480 .0525 .590 .0714 .30$}

580 Table 3 Changes of the gamma distribution parameters $\alpha$ and $\beta$ in each station and season during 1959 to 2016. $Z$ : $Z$ values from the $\mathrm{M}-\mathrm{K}$ test. When $\mathrm{Z}$ is bigger than 0 , the trend is upward; when $\mathrm{Z}$ is smaller than 0 , the trend is downward. When the absolute value of $\mathrm{Z}$ is bigger than or equal to $1.28,1.64$, and 2.32 , it means that the test has passed the reliability test of $90 \%, 95 \%$, and $99 \%$, respectively. Tr: trend of $\alpha$ and $\beta$, increasing $(\uparrow)$ : when the M-K statistic is positive and the confidence level is below 0.05 . Decreasing ( $\downarrow$ ): when the MannKendall statistic is negative and the confidence level is below 0.05. No trend (--): there is no trend detected according to the confidence level.

\begin{tabular}{|c|c|c|c|c|c|c|c|c|c|c|c|c|c|c|c|c|}
\hline \multirow{3}{*}{ station } & \multicolumn{4}{|c|}{ spring } & \multicolumn{4}{|c|}{ summer } & \multicolumn{4}{|c|}{ autumn } & \multicolumn{4}{|c|}{ winter } \\
\hline & & $\alpha$ & & & & & & & & $\alpha$ & & & & i & & \\
\hline & $\operatorname{Tr}$ & $\mathrm{Z}$ & $\operatorname{Tr}$ & $\mathrm{Z}$ & $\operatorname{Tr}$ & Z & $\operatorname{Tr}$ & Z & $\operatorname{Tr}$ & Z & $\operatorname{Tr}$ & $\mathrm{Z}$ & $\operatorname{Tr}$ & Z & $\operatorname{Tr}$ & $\mathrm{Z}$ \\
\hline Yf & $\downarrow$ & -3.05 & $\uparrow$ & 2.99 & -- & 0.74 & -- & 0.36 & -- & -0.17 & -- & 0.00 & -- & 0.09 & -- & 1.16 \\
\hline $\mathrm{Lh}$ & -- & -1.69 & $\uparrow$ & 1.99 & -- & 1.05 & -- & -0.76 & -- & -1.31 & -- & 1.89 & -- & -0.52 & -- & 1.01 \\
\hline Yc & $\downarrow$ & -2.76 & -- & 1.20 & -- & 0.74 & -- & 1.74 & -- & -1.63 & -- & 1.77 & -- & -0.65 & -- & 0.74 \\
\hline $\mathrm{Ja}$ & -- & -1.00 & -- & 0.78 & -- & 1.11 & -- & 0.32 & -- & -1.92 & $\uparrow$ & 2.21 & -- & -0.79 & $\uparrow$ & 2.33 \\
\hline Jgs & $\downarrow$ & -2.46 & -- & 1.37 & -- & -0.21 & -- & 1.58 & $\downarrow$ & -2.29 & -- & 1.11 & $\downarrow$ & -2.82 & $\uparrow$ & 3.60 \\
\hline $\mathrm{Sc}$ & $\downarrow$ & -2.18 & -- & 1.62 & -- & 0.79 & -- & 0.89 & -- & -1.84 & -- & 1.56 & -- & -0.43 & $\uparrow$ & 2.36 \\
\hline Gx & -- & -1.20 & -- & 1.19 & -- & -0.76 & -- & 0.42 & -- & -1.49 & -- & 0.08 & -- & -0.64 & $\uparrow$ & 2.35 \\
\hline $\mathrm{Nc}$ & $\downarrow$ & -2.42 & -- & 1.40 & -- & 1.91 & -- & 0.23 & -- & -0.08 & -- & 0.45 & -- & 1.05 & -- & 1.14 \\
\hline Zs & $\downarrow$ & -2.35 & $\uparrow$ & 2.11 & -- & 1.67 & -- & 0.87 & -- & -1.29 & $\uparrow$ & 2.75 & -- & 0.20 & -- & 0.71 \\
\hline Yof & -- & -1.78 & -- & 0.72 & -- & 0.01 & -- & 0.87 & $\downarrow$ & -2.49 & $\uparrow$ & 2.69 & -- & -1.09 & $\uparrow$ & 2.93 \\
\hline $\mathrm{Nd}$ & $\downarrow$ & -2.15 & $\uparrow$ & 2.18 & -- & -0.39 & -- & 1.12 & -- & -1.19 & -- & 1.33 & -- & -1.73 & $\uparrow$ & 3.10 \\
\hline $\mathrm{Ln}$ & -- & -0.83 & $\uparrow$ & 2.54 & -- & -0.21 & -- & 0.08 & $\downarrow$ & -2.13 & -- & 0.65 & -- & -1.14 & -- & 1.73 \\
\hline
\end{tabular}

Table 4 Mean threshold values $(\mathrm{mm})$ of $12-\mathrm{H}$ in each station and seasons and their estimates obtained from the gamma distribution according data in 1959-2016. pre 99 indicates thresholds from the observed precipitation and gam 99, the estimates from gamma distribution. 
https://doi.org/10.5194/nhess-2021-412

Preprint. Discussion started: 23 February 2022

(c) Author(s) 2022. CC BY 4.0 License.

\begin{tabular}{lcccccccc}
\hline \multirow{2}{*}{ station } & \multicolumn{2}{c}{ spring } & \multicolumn{2}{c}{ summer } & \multicolumn{2}{c}{ autumn } & \multicolumn{2}{l}{ winter } \\
\cline { 2 - 8 } & pre_99 & gam_99 & pre_99 & gam_99 & pre_99 & gam_99 & pre_99 & gam_99 \\
\hline Yf & 38.88 & 38.77 & 45.93 & 45.79 & 23.66 & 23.52 & 17.17 & 17.11 \\
Lh & 36.71 & 36.60 & 42.33 & 42.15 & 19.97 & 19.79 & 16.72 & 16.65 \\
Yc & 35.03 & 34.91 & 40.94 & 40.77 & 21.97 & 21.84 & 16.57 & 16.51 \\
Ja & 34.96 & 34.88 & 41.08 & 40.96 & 20.29 & 20.16 & 16.08 & 16.00 \\
Jgs & 31.58 & 31.48 & 46.97 & 46.86 & 27.32 & 27.15 & 14.31 & 14.23 \\
Sc & 28.85 & 28.79 & 37.59 & 37.49 & 25.78 & 25.58 & 14.31 & 14.22 \\
Gx & 34.32 & 34.23 & 37.17 & 37.05 & 20.02 & 19.87 & 16.87 & 16.77 \\
Nc & 38.39 & 38.24 & 49.09 & 48.89 & 20.04 & 19.84 & 17.38 & 17.31 \\
Zs & 38.06 & 37.97 & 47.98 & 47.78 & 20.87 & 20.71 & 18.39 & 18.29 \\
Yof & 37.92 & 37.81 & 46.23 & 46.03 & 20.90 & 20.68 & 18.04 & 17.96 \\
Nd & 42.33 & 42.22 & 46.05 & 45.84 & 23.72 & 23.52 & 16.92 & 16.84 \\
Ln & 37.89 & 37.76 & 41.76 & 41.56 & 21.20 & 21.06 & 15.99 & 15.88 \\
\hline & & & & & & & & \\
\hline
\end{tabular}

Table 5 Statistics of extreme precipitation events from 1-10 runs at Ganxian station from 2009 to 2014

\begin{tabular}{|c|c|c|c|c|c|c|c|c|c|c|c|c|c|}
\hline \multirow{2}{*}{ Runs } & \multirow{2}{*}{ seasons } & \multicolumn{5}{|c|}{ Scenario } & \multirow{2}{*}{ Runs } & \multirow{2}{*}{ seasons } & \multicolumn{5}{|c|}{ Scenario } \\
\hline & & 0.5 & 0.2 & 0.1 & 0.05 & 0.02 & & & 0.5 & 0.2 & 0.1 & 0.05 & 0.02 \\
\hline 1 & spring & 13 & 9 & 6 & 6 & 2 & 6 & spring & 10 & 6 & 4 & 1 & 1 \\
\hline 1 & summer & 12 & 11 & 9 & 6 & 5 & 6 & summer & 5 & 5 & 3 & 2 & 1 \\
\hline 1 & autumn & 4 & 2 & 1 & 1 & 1 & 6 & autumn & 2 & 1 & 1 & 1 & 1 \\
\hline 1 & winter & 1 & 1 & 1 & 1 & 1 & 6 & winter & 2 & 2 & 1 & 1 & 1 \\
\hline 2 & spring & 11 & 9 & 6 & 3 & 1 & 7 & spring & 11 & 5 & 3 & 2 & 2 \\
\hline 2 & summer & 10 & 8 & 6 & 4 & 2 & 7 & summer & 6 & 3 & 3 & 2 & 1 \\
\hline 2 & autumn & 1 & 1 & 1 & 1 & 1 & 7 & autumn & 2 & 1 & 1 & 1 & 1 \\
\hline 2 & winter & 1 & 1 & 1 & 1 & 1 & 7 & winter & 2 & 2 & 2 & 2 & 2 \\
\hline 3 & spring & 8 & 7 & 4 & 2 & 2 & 8 & spring & 8 & 5 & 2 & 1 & 1 \\
\hline 3 & summer & 9 & 7 & 4 & 4 & 2 & 8 & summer & 4 & 3 & 3 & 2 & 1 \\
\hline
\end{tabular}


https://doi.org/10.5194/nhess-2021-412

Preprint. Discussion started: 23 February 2022

(c) Author(s) 2022. CC BY 4.0 License.

\begin{tabular}{lcccccc|ccccccc}
3 & autumn & 2 & 1 & 1 & 1 & 1 & 8 & autumn & 1 & 1 & 1 & 1 & 1 \\
3 & winter & 2 & 1 & 1 & 1 & 1 & 8 & winter & 2 & 2 & 2 & 2 & 2 \\
4 & spring & 9 & 7 & 4 & 3 & 3 & 9 & spring & 6 & 4 & 4 & 1 & 1 \\
4 & summer & 8 & 5 & 4 & 2 & 2 & 9 & summer & 4 & 4 & 3 & 2 & 1 \\
4 & autumn & 2 & 1 & 1 & 1 & 1 & 9 & autumn & 1 & 1 & 1 & 1 & 1 \\
4 & winter & 2 & 2 & 2 & 2 & 2 & 9 & winter & 1 & 1 & 1 & 1 & 1 \\
5 & spring & 8 & 7 & 5 & 2 & 2 & 10 & spring & 7 & 5 & 4 & 1 & 1 \\
5 & summer & 5 & 2 & 1 & 1 & 1 & 10 & summer & 3 & 3 & 3 & 2 & 1 \\
5 & autumn & 2 & 2 & 1 & 1 & 1 & 10 & autumn & 1 & 1 & 1 & 1 & 1 \\
5 & winter & 2 & 1 & 1 & 1 & 1 & 10 & winter & 1 & 1 & 1 & 1 & 1 \\
\hline
\end{tabular}

Table 6 Floods events recorded in Hanlinqiao hydrological station from 2009 to 2014

\begin{tabular}{cccccc}
\hline Year & spring & summer & autumn & winter & Total \\
\hline 2009 & 0 & 1 & 0 & 0 & 1 \\
2010 & 2 & 1 & 0 & 0 & 3 \\
2012 & 2 & 1 & 0 & 0 & 3 \\
2013 & 1 & 1 & 0 & 0 & 2 \\
2014 & 2 & 1 & 0 & 0 & 3 \\
Total & 7 & 5 & 0 & 0 & 12 \\
\hline
\end{tabular}

